\title{
Attribution Therapy: Effects of Locus of Control and Timing of Treatment
}

\author{
Elizabeth Mitchell Altmaier and Mark R. Leary \\ University of Florida
}

\author{
Donelson R. Forsyth \\ Virginia Commonwealth University
}

James C. Ansel

University of Florida

\begin{abstract}
The reduction of debilitating self-blame following negative events through the use of attribution therapy was investigated. After receiving harsh personal criticism from a peer, participants were given information that suggested this negative event was caused by an external factor. Results indicated that the effectiveness of attribution therapy depended on when the intervention occurred and the locus of control orientation of the participant. In general, externals' ratings of self-evaluation were not influenced by the intervention, but internals evidenced greater self-acceptance when the intervention occurred prior to the negative evaluation or was postponed. It was concluded that attribution therapy is most effective when the attributional information is made salient to the individual.
\end{abstract}

Problems in personal adjustment can often be traced to the attributions individuals make regarding the causes of their behaviors (cf. Abramson, Seligman, \& Teasdale, 1978; Valins \& Nisbett, 1971). Although the failure to deal satisfactorily with environmental stresses and demands generally leads to loss of self-esteem and self-confidence, these effects are far more pronounced when the cause of the failure is attributed to oneself. Such negative selfattributions, whether veridical or erroneous, lead to feelings of inadequacy and further undermine the individual's ability to deal effectively with subsequent problems (Storms \& McCaul, 1976).

Recent research and theoretical reformulations of learned helplessness emphasize the relationship between causal attributions and ability to deal with negative outcomes. For example, Dweck and Reppucci (1973) found that students who believed their failures on mathematics problems were caused by their own incompetence expected to fail on subsequent tasks and were less motivated to succeed. Similarly, Klein, Fencil-Morse, and Seligman (1976) found that depressed

Requests for reprints should be sent to Elizabeth Mitchell Altmaier, Department of Psychology, University of Florida, Gainesville, Florida 32611. subjects who attributed failure at anagrams to their own incompetence rather than to the difficulty of the test demonstrated less adequate patterns of adjustment. As $\mathrm{Ab}$ ramson et al. (1978) noted, uncontrollable outcomes can lead to feelings of helplessness, but this helplessness is even more debilitating when attributed to personal inabilities rather than to environmental factors.

One of the most significant implications of the attributional analysis of maladjustment concerns recommendations for counseling. If clients can be provided with information that leads them to formulate attributional conclusions that promote adjustment, then the link between stressful life events and self-rejection can be weakened. Supporting the effectiveness of attribution therapy (cf. Abramson et al., 1978; Davidson, 1969; Ross, Rodin, \& Zimbardo, 1969; Valins \& Nisbett, 1971), Dweck (1975) found that individuals in an academic setting trained to attribute their failure to a controllable factor (lack of effort) performed more adequately than those who attributed failure to lack of ability. Similarly, Tennen and Eller (1977) found that when subjects attributed failure to the difficulty of the task, subsequent coping was more adequate than when failure was attributed to personal inability. 
Other research, however, has failed to support the usefulness of attribution-based therapies. For example, some studies that attempted to manipulate directly attribution of causality for aversive outcomes (Hanusa \& Schulz, 1977; Wortman, Panciera, Shusterman, \& Hibscher, 1976) found that subjects who attributed these events to lack of ability performed more adequately than those who attributed the events to situational factors. Also, Bulman and Wortman (1977), in a study of patients recovering from severe accidents, found the personal attribution of causality for the accident correlated with more adequate coping.

'The inconsistency of these past research findings may stem from the failure to consider the effect of initial attributions on acceptance of later attributional information. For example, clients who typically explain their behavior in terms of external causes may be less affected by suggestions that an event is to be attributed externally than clients who generally focus on internal determinants of their behavior. These individual differences in initial attributional tendencies form the basis of Rotter's (1966) concept of locus of control. Locus of control is a generalized expectation regarding the source of reinforcements, emphasizing externality at one extreme and internality at the opposite extreme. Internals assume that their outcomes are primarily determined by their own abilities and efforts, whereas externals emphasize the importance of external factors, including luck and chance.

The current investigation attempted to determine the effect of attribution therapy on the self-evaluations of internally and externally oriented individuals following interpersonal failure. A laboratory analogue was developed that incorporated a strongly stressful interpersonal situation and the major elements of an attribution therapy intervention. The stressful situation involved receiving an extremely negative and condemnatory evaluation from a new acquaintance; the intervention analogue included being provided with a plausible external attribution for the perceived interpersonal failure. Since externals typically make external attributions, information given to them that a negative life event was due to external factors, rather than to themselves, would not be expected to have much of an effect. However, such information should prompt internals, who are predisposed to attribute outcomes to themselves more strongly, to adopt an external attribution (cf. Davis \& Davis, 1972; Phares, Wilson, \& Klyver, 1971).

The effectiveness of attribution therapy, however, may also depend on the timing of the therapeutic intervention. Attributional information should prevent negative selfevaluation most effectively when it is presented to a client prior to the negative experience; such information would presumably serve as a preventative therapeutic inoculation against the negative experience and hence provide the client with an attributional framework for defining the experience in a less stressful manner as it occurs. However, providing attributional information to the client after the negative experience has been the tradition of attribution therapy, and has, in fact, been found effective (e.g., Abramson et al., 1978; Tennen \& Eller, 1977). A related purpose of this investigation, then, was to compare the effectiveness of attribution therapy administered before the stressful event to that administered after the event. Two conditions of delay were utilized: a brief delay, corresponding to a crisis intervention condition, and a longer delay, corresponding to counseling further removed in time from the stressful event.

\section{Method}

\section{Subjects}

Forty males and 72 females recruited from introductory psychology classes participated in the experiment. Prior to experimental participation, subjects had completed in their psychology classes the Personal Orientation Scale (Schopler, Langmeyer, Stokols, \& Reisman, 1973), a measure of locus of control. Two male and two female experimenters, randomly assigned across experimental sessions, individually conducted the sessions; all subjects received class credit for the research experience. Two male and two female undergraduate students served as confederate subjects. They were also randomly assigned across sessions. 


\section{Procedure}

When a subject arrived for the experiment, he or she was joined by a confederate posing as another subject. The experimenter then greeted the two "subjects" and briefly described the study. He or she explained that in order to investigate the initial phases of the acquaintance process, the participants would talk together for several minutes. One person, supposedly selected at random, would be the "interviewer," who would ask questions, while the other would be the "interviewee." As a result of a rigged, but seemingly fair, drawing, the confederate was designated interviewer. The experimenter gave the confederate a list of 12 questions to follow during the conversation; these questions covered demographic and background information, future career plans and goals, and feelings about meeting new people and belonging to groups. The interviewer was told he or she would record his or her perceptions of the interviewee after their conversation, and the subject was told that he or she would be asked later to comment on the interviewer's accuracy of perception.

The subject and confederate were then taken to another room, where the confederate asked the subject the series of questions and discussed the subject's responses with him or her. After 10 minutes, the experimenter returned and asked the confederate to write a concise and frank evaluation of the subject. When the confederate was finished writing the evaluation, the subject was escorted to the original room, where he or she read the interviewer's evaluation and completed ratings of him- or herself and the interviewer's evaluation.

All subjects were given a standard negative evaluation, which stated,

She [he] is a nice person, but I had trouble really understanding her [him] and where she [he] was coming from. She [he] was kind of confused and what she [he] said didn't seem very consistent. Also, on a more personal level, her [his] ideas were not very exciting. It was difficult to keep paying attention. If I had met her [him] somewhere else, like in a class, I don't think I would have wanted to get to know her [him].

In addition to this evaluation, subjects in the experimental conditions were given attributional information designed to help them deal with this negative appraisal: The experimenter explained that undergraduate students are typically overly harsh in their perceptions of others, tending to be "very critical of other students when they evaluate them after a brief contact." In the prevention condition, subjects were given the attributional information before the handwritten copy of the confederate's evaluation. In the immediate intervention condition, subjects were warned immediately after reading the evaluation. Delayed intervention subjects, on the other hand, were not given the attributional information until they had nearly completed their selfratings. At that point the experimenter explained that this information had been left out by oversight, so they would need to start over again on the questionnaire (the original form was collected and destroyed while the subject watched). Lastly, subjects in the control con- dition received no information and simply completed the questionnaire after receiving the confederate's evaluation.

The questionnaire respondents completed consisted of (a) four Likert-type measures of self-evaluation (ability to communicate well and ability to be personally attractive to others) and of interviewer's perceptiveness (estimation of interviewer accuracy and estimation of potential interviewer bias) and (b) a behavioroid measure of willingness to be reinterviewed. Once subjects had completed the questionnaires, they were thoroughly debriefed, asked not to discuss the study with other introductory psychology students, and thanked for their participation.

\section{Results}

Subjects' scores on the Personal Orientation Scale were used to classify them as either internal or external in locus of control. The Personal Orientation Scale contains 25 items to which the individual responds on a 5-point Likert response scale. The scale shows evidence of adequate validity and reliability (Schopler et al,, 1973). By performing a median split (median score $=72$ ) on the Personal Orientation Scale scores, subjects could be classified as internal or external in their locus of control. Therefore, the dependent measures were examined using 2 (locus of control-internal, external) $\times 4$ (therapy-control, prevention, immediate intervention, delayed intervention) multivariate and univariate analyses of variance. Because the number of subjects serving in each cell of the design was unequal, these analyses adjusted each effect for those of equal or lower order. Pillai's (1965) trace was used as the approximation for the $F$ ratio in the multivariate analyses.

\section{Self-Evaluations}

Analysis of the four questionnaire measures of self-evaluation (ability to communicate well, ability to attract others, estimation of interviewer bias, and estimation of interviewer accuracy) revealed a significant multivariate interaction of locus of control and therapy, $F(12,315)=2.22, p<$ .01 . In order to clarify the meaning of this interaction, standardized composite scores were computed for each subject using the discriminant function weights generated in 
Table 1

Internals' and Externals' Self-Evaluations

\begin{tabular}{lcccc}
\hline & \multicolumn{5}{c}{ Therapy condition } \\
\cline { 2 - 5 } $\begin{array}{c}\text { Locus of } \\
\text { control }\end{array}$ & $\mathrm{C}$ & $\mathrm{P}$ & $\mathrm{II}$ & $\mathrm{DI}$ \\
\hline Internal & -.216 & -.107 & -.288 & .150 \\
External & -.058 & -.159 & -.024 & -.318 \\
\hline
\end{tabular}

Note. Means are multivariate composite scores; higher scores indicate more positive self-evaluations. Abbreviations: $\mathrm{C}=$ control; $\mathbf{P}=$ prevention; $\mathrm{II}=$ immediate intervention; $\mathrm{DI}=$ delayed intervention.

the multivariate analysis. ${ }^{1}$ These composite scores, which reflect overall self-evaluation broken down by locus of control and therapy, are presented in Table 1. Multivariate simple effects tests-the multivariate counterpart of simple effects conducted to investigate univariately significant interactions-indicated that internals evaluated themselves more positively than externals when intervention was delayed, $F(4,103)=$ $2.91, p<.02$. However, immediate intervention reversed this effect so that externals rated themselves more positively than internals, $F(4,103)=2.29, p<.06$. Thus, internals' self-ratings were far more positive when intervention was delayed rather than immediate, $t(106)=2.90, p<.05$. The means for internal and external controls differed in the direction predicted, but this difference did not reach significance $(p<$ .15). Lastly, no locus of control differences were obtained in the prevention treatment condition.

Table 2

Means and Standard Deviations of Volunteered Future Interviews

\begin{tabular}{cllll}
\hline & \multicolumn{4}{c}{ Therapy condition } \\
\cline { 2 - 5 } $\begin{array}{c}\text { Locus of } \\
\text { control }\end{array}$ & $\mathrm{C}$ & $\mathrm{P}$ & $\mathrm{II}$ & $\mathrm{DI}$ \\
\hline Internal & & & & \\
$M$ & $2.54_{\mathrm{c}}$ & $4.64_{\mathrm{a}}$ & $2.90_{\mathrm{b}, \mathrm{c}}$ & $3.60_{\mathrm{b}, \mathrm{c}}$ \\
$S D$ & 2.22 & 1.63 & 2.28 & 2.27 \\
External & & & & \\
$M$ & $3.72_{\mathrm{b}}$ & $2.80_{\mathrm{c}}$ & $3.42_{\mathrm{b}, \mathrm{c}}$ & $2.85_{\mathrm{b}, \mathrm{c}}$ \\
$S D$ & 2.19 & 1.88 & 2.09 & 1.72 \\
\hline
\end{tabular}

Note. Means with different subscripts are significantly different from one another by Duncan's multiple-range test $(p=$ .05). Abbreviations: $\mathrm{C}=$ control; $\mathrm{P}=$ prevention; $\mathrm{II}=\mathrm{im}$ mediate intervention; $\mathrm{DI}=$ delayed intervention.

\section{Behavioral Assessment}

A two-way interaction of therapy and locus of control was also obtained on the number of future interviews that subjects indicated they would be willing to give, $F(3$, $106)=3.08, p<.03$. As Table 2 indicates, the means for this interaction follow the same pattern as the interaction means for self-ratings, except in the prevention condition. Although the mean for internals was only slightly higher than the mean for externals on self-ratings, this difference was far more pronounced for the behavioral measure. When attributional information was given prior to receiving the negative feedback, internals offered to participate in more interviews than did externals $(p<.05)$. In fact, internals volunteered for significantly more interviews in the prevention therapy condition compared with the control condition $(p<.05)$. As was found for self-evaluations, externals volunteered for more interviews than did internals when no attributional information was provided.

\section{Discussion}

Subjects in the present study were all exposed to a stressful interpersonal experience involving a negative evaluation from a peer. As predicted, individuals' locus of control orientation, apart from any therapeutic intervention, was found to be related to selfacceptance following the negative event. External locus of control subjects in the control condition evaluated themselves more positively and volunteered to return for a greater number of interviews than did internal locus of control subjects. This finding extends previous research that shows that externals engage in greater defensive externalization following failures than do internals (e.g., Davis \& Davis, 1972; Phares et al., 1971; cf. Gilmor \& Minton, 1974). Apparently, externals reduce the personal relevance of negative events by attributing the event to external factors.

1 The standardized composite score for the $j$ th subject $=\sum_{i=1}^{4} w_{\mathrm{i}} S_{\mathrm{i}}$, where $w$ is the maximally discriminating weight for the $i$ th dependent variable and $S$ is the $j$ th subject's standardized score on that dependent variable (see Harris, 1975). 
Predictions concerning the effects of timing of attribution treatment and locus of control orientation of participants were only partially supported. On both the self-evaluation and behavioral measures, preventive therapy (providing attribution before the negative evaluation) appeared to aid internals, while having a deleterious effect upon externals. Specifically, internals who were given a way to deal with failure prior to its occurrence (a) improved their self-evaluations (nonsignificantly) compared with internals in the control condition, (b) volunteered for more interviews than internal controls, and (c) volunteered for more interviews than externals in the preventive condition. When subjects were forewarned that the evaluation was probably a reflection of the situation and not of themselves, internalization of the feedback seems to have been weakened. As a result, the possibility of negative evaluations in future interviews may not have been perceived as personally threatening, so that internals in the prevention condition were more likely to volunteer. Potentially, providing internal clients with external attributions for occasional stressful events is of benefit, but it seems unlikely that this strategy would be useful with clients who normally make external attributions.

When the attribution therapy occurred immediately after the negative evaluation, externals rated themselves more highly than internals. However, when the therapy was delayed, the attribution information significantly benefited the internal locus of control subjects. Internals in the delayed intervention condition rated themselves more positively than (a) externals in the delayed intervention condition and (b) internals in the immediate intervention condition. These results suggest that attributional intervention may be most effective, at least for internal clients, when they have had time to assess the situation on their own prior to receiving the attributional information. If internal clients are allowed time to make an internal attribution for a negative event, subsequent information that indicates that the event was due to external factors rather than to themselves may be greatly anxietyreducing and result in a rebound effect.
However, in delayed counseling situations, maintaining the external attributions of an external locus of control client may be the preferred treatment.

It should also be noted that the attributional information provided in the delayed intervention condition was particularly salient to the subjects. In that condition, the importance of the information was attested to by the fact that the experimenter felt it necessary to ask the subjects to reevaluate themselves after it was revealed. This emphasis on the importance of the attributional information may have led to internals' increased incorporation of the attributional content into their attributions. Potential counseling strategies that increase information salience for the client should be explored within the context of locus of control.

The results of this research thus yield mixed support for the prediction that attribution-based therapy will be differentially effective depending on the locus of control orientation of the client. Although attribution therapy appears to be an effective strategy to adopt in certain instances, further research is required to specify exactly those factors that influence its effectiveness. In the current investigation, individuals faced with a negative interpersonal evaluation were directed to attribute the event to external rather than internal sources. An alternative strategy might be to direct clients to attribute outcomes to factors they can control, whether these factors are internal or external (cf. Wortman \& Dintzer, 1978). In addition, part of the failure of the intervention therapy to improve externals' self-acceptance may have been due to neglecting to differentiate between "true" externals and "defensive" externals (cf. Hochreich, 1974), and to the use of a therapeutic attributional statement that did not differ from externals' everyday causal ascriptions. It is possible that externals may benefit more from attributional information that emphasizes controllable internal causes rather than external causes. In general, however, the current study attests to the potential efficacy of attribution therapy, and it remains for future research to more clearly specify its limits and full effectiveness. 


\section{References}

Abramson, L. Y., Seligman, M. E. P., \& Teasdale, J. D. Learned helplessness in humans: Critique and reformulation. Journal of Abnormal Psychology, $1978,87,49-74$.

Bulman, R. J., \& Wortman, C. B. Attributions of blame and coping in the "real world": Severe accident victims react to their lot. Journal of Personality and Social Psychology, 1977, 35, 351-363.

Davidson, G. C. Appraisal of behavior modification techniques with adults in institutional settings. In C. M. Franks (Ed.), Behavior therapy: Appraisal and status. New York: McGraw-Hill, 1969.

Davis, W. L., \& Davis, D. E. Internal-external control and attribution of responsibility for success and failure. Journal of Personality, 1972, 40, 123-135.

Dweck, C.S. The role of expectations and attributions in the alleviation of learned helplessness. Journal of Personality and Social Psychology, 1975, 31, 674-685.

Dweck, C. S., \& Reppucci; N. D. Learned helplessness and reinforcement responsibility in children. Journal of Personality and Social Psychology, 1973, $25,109-116$.

Gilmor, T. M., \& Minton, H. L. Internal versus external attribution of task performance as a function of locus of control, initial confidence, and success-failure outcome. Journal of Personality, 1974, 42, 159-174.

Hanusa, B. H., \& Schulz, R. Attributional mediators of learned helplessness. Journal of Personality and Social Psychology, 1977, 35, 602-611.

Harris, R. J. A primer of multivariate statistics. New York: Academic Press, 1975.

Hochreich, D. J. Defensive externality and attribution of responsibility. Journal of Personality, 1974, 42, 543-557.

Klein, D. C., Fencil-Morse, E., \& Seligman, M. E. P. Learned helplessness, depression, and the attribution of failure. Journal of Personality and Social Psychology, 1976, 33, 508-516.
Phares, E. J., Wilson, K. G., \& Klyver, N. W. Internal-external control and the attribution of blame under neutral and distractive conditions. Journal of Personality and Social Psychology, 1971, 18, 285-288.

Pillai, K. C. S. On the distribution of the largest characteristics root of a matrix in multivariate analysis. Biometrika, 1965, 52, 405-414.

Ross, L. D., Rodin, J., \& Zimbardo, P. G. Toward an attribution therapy: The reduction of fear through induced cognitive-emotional misattribution. Journal of Personality and Social Psychology, 1969, 12, 279-288.

Rotter, J. B. Generalized expectancies for internal versus external control of reinforcement. Psychological Monographs, 1966, 80(1, Whole No. 609).

Schopler, J., Langmeyer, D., Stokols, D., \& Reisman, S. The North Carolina I-E scale: Validation of the short form. Research Previews, 1973, 20, 3-12.

Storms, M. D., \& McCaul, K. D. Attribution processes and emotional exacerbation of dysfunctional behavior. In J. H. Harvey, W. J. Ickes, \& R. F. Kidd (Eds.), New directions in attribution research (Vol. 1). Hillsdale, N.J.: Erlbaum, 1976.

Tennen, H., \& Eller, S. J. Attributional components of learned helplessness and facilitation. Journal of Personality and Social Psychology, 1977, 35, 265271.

Valins, S., \& Nisbett, R. E. Attribution process in the development and treatment of emotional disorders. Morristown, N.J.: General Learning Press, 1971.

Wortman, C. B., \& Dintzer, L. Is an attributional analysis of the learned helplessness phenomenon viable?: A critique of the Abramson-SeligmanTeasdale reformulation. Journal of Abnormal Psychology, 1978, 87, 75-90.

Wortman, C. B., Panciera, L., Shusterman, L., \& Hibscher, J. Attributions of causality and reactions to uncontrollable outcomes. Journal of Experimental Social Psychology, 1976, 12, 301-316.

Received April 27, 1979 